\title{
Traditional logic, modern logic and natural language
}

\author{
Wilfrid Hodges \\ Herons Brook, Sticklepath, \\ Okehampton, Devon EX20 2PY, England \\ wilfrid.hodges@btinternet.com \\ DRAFT June 2009. The paper is for a Festschrift and this draft has \\ removed a number of personal references.
}

\section{The questions}

... Wikipedia [38] defines: traditional logic is 'a loose name for the way of doing logic that began with Aristotle, and that was dominant until the advent of modern predicate logic in the late nineteenth century'. It is of great interest to place the transitions between traditional and modern logic. In this paper I will say where I think the main differences lie. In my last section I will comment on ... the relationship between some traditional argument forms and natural language argument.

The strength of traditional logic is sometimes measured in terms of the valid inference patterns that it recognises. Among other patterns:

(1) "Some $P R$ all $Q$ " implies "All $Q$ are $R$-ed by some $P$ ".

and the pattern behind some inferences that De Morgan studied:

(2) "All horses are animals. So, all horse tails are animal tails.".

This is not a new measure; it was widely used in the mid 20th century to gauge the strength of various early logicians, among them Aristotle, Boethius and Ockham. But I have my doubts about it. We first need to see how traditional logic used its inference patterns. Until we know that, we don't know that we are comparing them with the right things in modern logic. 
From early times Euclid's Elements was considered one of the pinnacles of human reasoning. (For modern mathematicians this is odd: Archimedes was clearly light-years ahead of Euclid. But that wasn't the traditional perception.) Aristotelian logicians believed that syllogisms accounted for all forms of logical reasoning, and hence by implication for all the logical steps in the Elements. Some platonists dissented: geometry also needs spatial intuitions. But it was never clear-perhaps even in the case of Kant-whether the claim was that spatial intuition gives new logical methods rather than geometrical axioms. So apparently neither aristotelians nor platonists saw any knock-down refutation of the claim that all the reasoning steps in Euclid can be justified in terms of syllogisms. If, as historians of logic, we want to maintain that traditional logic falls far short of justifying Euclid's inferences, then we need to explain why for two thousand years nobody called attention to the emperor's clothes.

For example one sees the view expressed that traditional logic is obviously unable to handle geometry because traditional logic is monadic and geometry involves relations. But bear in mind who we are talking about: the list includes Proclus, Ibn Sīnā, Tūsī, Leibniz, Wallis, John Bernoulli, Euler, Gergonne. Most of these people were leading specialists in geometry, logic or both, and all of them were competent in both fields. Any view like this one, that by implication makes them out to be a bunch of intellectual time-servers, should never have been allowed off the starting block.

There is a lot to discuss below. In cutting down the length I may have said too little about some questions. I hope to develop several of the points below in greater detail elsewhere, if it turns out that they are both new and correct.

\section{Aristotle's use of logic}

In the mid fourth century BC, Aristotle introduced the idea that one can check arguments by showing that they conform to one of a set of valid argument patterns. The main patterns that he used are the categorical syllogisms, for example

If $A$ belongs to no $B$ but to some $C$, it is necessary that $B$ does not belong to some $C$.

(Cf. Prior Analytics i.5, 27a32, [2] p. 44.) Today we find it more convenient to phrase this pattern as follows:

(4) No $B$ is an $A$. Some $C$ is an $A$. Therefore some $C$ is not a $B$. 
Aristotle himself also considered modal syllogisms, and later traditional logicians added propositional syllogisms to the stock of valid argument patterns.

How exactly did one check an argument with the help of these patterns? Aristotle said very little about this in his surviving texts. But he, or perhaps his editor Andronicus, collected some information about it in the later sections of Book One of the Prior Analytics. There we learn that, faced with a natural language argument like

God doesn't have times that need to be set aside for action. God does have right moments for action. Therefore some right moment for action is not a time that needs to be set aside for action.

Aristotle would find the premises and the conclusion, and then write out the syllogistic terms together with letters to stand for them:

$A$ : thing that God has. $B$ : time needing to be set aside for action. $C$ : right moment for action.

(This is from Prior Analytics i.35f. Aristotle's text needs careful dissection, and for a smooth exposition I've permuted some of his material.) Aristotle refers to the correlation of terms and letters as 'setting out the terms' (ékthesis tôn horôn, not to be confused with the method of argument known as ékthesis). Then he would indicate which syllogistic mood the argument was supposed to conform to, unless this was obvious. (For the syllogism (6) the mood is (5) above.)

So far, his practice seems almost identical with what we do today in elementary logic classes. For example Gamut [13] (p. 67) sets out terms as follows:

$\mathrm{B}_{2}$ : lies between

b: Breda, t: Tilburg, e: Eindhoven

From modern experience we know what comes next, though Aristotle's text doesn't discuss it. The student has to check that the relevant valid sequent becomes a correct paraphrase of the original argument if we read the nonlogical constant symbols in the sequent as meaning what the setting out of terms says they mean. One way to check this is to rewrite the sequent with the symbols replaced by their natural language equivalents; the result is a natural language argument, maybe with some logical symbols like ' $\wedge$ ' for 'and'. For future reference I call this rewriting the formal paraphrase of the argument. For example the argument (5), with (4) as the relevant sequent, 
has the formal paraphrase

No (time needing to be set aside for action) is a (thing that God

has). Some (right moment for action) is a (thing that God has).

Therefore some (right moment for action) is not a (time needing

to be set aside for action).

Then the student uses her linguistic intuitions to check that the original argument and the formal paraphrase mean the same thing. This step of confirming the paraphrase is essential to complete the checking of the original argument, though today it is usually done silently and without writing out the formal paraphrase explicitly.

Besides the syllogisms, Aristotle also had a more sporadic collection of argument principles which he called topoi, 'topics' in English (cf. his book Topics, [2] pp. 167-277). He and his successors never integrated the topics with the syllogisms. In fact the list of topics varied from logician to logician, and there were persistent questions about whether topics are for validating arguments or for finding them, and whether they describe the forms or the subject-matter of arguments; Green-Pedersen [14] documents all this. But some topics certainly were used as patterns for valid arguments. One famous example, which we can trace back at least to Boethius [3] Book 3, 1198A4, takes the following form in Peter of Spain in the 13th century:

If one of the correlated things is posited, the other is posited.

(Peter of Spain, Tractatus [31] V para. 28.)

Peter illustrates it with the inference

(10) There is a father; therefore there is a son.

The inference (3) is a close analogue of a topical inference in Aristotle ('If knowledge is a belief, then also the object of knowledge is an object of belief', Topics ii.8 114a18f, [2] p. 190).

For completeness one should also mention Aristotle's conversion rules. These are one-premise inferences such as 'Every horse is an animal; therefore some animal is a horse'.

\section{Hilbert's observation}

In lectures in Göttingen in 1917-1921, David Hilbert assembled for the first time the syntax and semantics of first-order predicate logic (of course using 
earlier work of Peirce and others). In 1928 these lectures were published, after light editing, as a textbook with Ackermann [17]. Hilbert introduced monadic first-order logic by showing how it handles syllogisms ([17] ii.3). To introduce relational logic he showed how it handles the topical argument (10) above (or more strictly its converse, [17] iii.1, iii.3).

It might seem strange that Hilbert advertises first-order logic by showing it can handle arguments that Boethius could already manage in the 6th century. But see exactly what Hilbert says about this:

"If there is a son, then there is a father," is certainly a logically self-evident assertion, and we may demand of any satisfactory logical calculus that it make obvious this self-evidence, in the sense that the asserted connection will be seen, by means of the symbolic representation, to be a consequence of simple logical principles. ([17] iii.1)

Here Hilbert points to two differences between his modern logic and traditional logic.

First, his logic finds 'simple logical principles' that are adequate to support both syllogisms and relational topics. The traditional logicians never analysed their principles down to this level of simplicity. Hilbert is clearly right about this, and the point is quite fundamental.

Second, Hilbert's 'logical calculus' allows one to express complex ideas in a form where we can read off their implications by applying the simple logical principles. This is true but less telling. Having a formal calculus makes possible a number of logical tricks that were completely beyond the traditionals, for example nonstandard analysis and computerised proofchecking. But at the level of basic logic, the formal language is a convenience and a protection against error, and not much more than this. Weierstrass could reason logically and securely with ideas of great complexity, using only mathematical German and no logical calculus at all.

Michael Friedman [12] p. 474 notes that for reasoning about the continuum we need sentences of the form $\forall \ldots \forall \exists$, and he speaks of 'the absence of such logical forms' in Kant's logic. This is too fast. Certainly Kant had no formal calculus containing propositions of this form; but why should they have been missing from his German? Maybe he couldn't apply his logic to sentences of this complexity, but this is hardly because he lacked a formal language. ... 


\section{Local formalising}

Consider this, from Ibn Sīnā's autobiography:

As for the Elements of Euclid, I read the first five or six propositions ..., and thereafter undertook on my own to solve the entire remainder of the book. ... I read Logic and all the parts of philosophy once again. ... I compiled a set of files for myself, and for each argument that I examined, I recorded the syllogistic premisses it contained, the way in which they were composed, and the conclusions which they might yield, and I would also take into account the conditions of its premisses [i.e. their modalities] until I had Ascertained that particular problem. ... So I continued until all the Philosophical Sciences became deeply rooted in me and I understood them as much as is humanly possible. ... Having mastered Logic, Physics and Mathematics, I had now reached Theology. ... (Gutas [15] pp. 26-28.)

I draw two implications from this passage. The first is that Ibn Sinnā believed he could reduce Euclid's Elements to syllogisms. He claims this explicitly only for Aristotle's Organon, but the Organon already contains enough mathematics to occupy about a hundred pages of Thomas Heath's book on mathematics in Aristotle [16]. He would hardly have added that he had 'mastered Mathematics' if he thought that the Elements contained arguments that resisted this treatment.

The second is that Ibn Sīnā verified ('Ascertained' in Gutas' translation) the arguments in 'Logic and all the parts of philosophy' by breaking them down into pieces that he could treat as syllogisms, and then recording each syllogism separately on a file card. This is very much in tune with the way he deploys syllogisms when he is analysing philosophical theses; see Gutas' analysis in [15] pp. 177-181. In short, Ibn Sīnā verifies (and hence formalises) each syllogism separately. In a typical logic course today we treat arguments quite differently: we choose a symbolism that fits the whole argument, and we deduce the conclusion from the premises by formal derivations that can be very much more complex than a single syllogism.

Let us refer to Ibn Sīnā's procedure, where each syllogism is checked separately, as local formalisation; the modern approach is global formalisation.

To avoid misunderstandings, let me clarify at once that the contrast lo$\mathrm{cal} /$ global is not the same as the contrast small-scale/large-scale. For example Aristotle in Prior Analytics i.25 discusses arguments that can be analysed into a tree of syllogisms. The conclusion of the argument is the con- 
clusion of the bottom syllogism, which (to adapt a term from Aristotle) we can call the 'leading' (kúrios) syllogism. The leading syllogism could well take control of the large-scale form of the argument. Thus

We will prove that right moments for action don't have to be times that need to be set aside for action For this we first show that God doesn't have times that need to be set aside for action (13) (and here follows a string of subsidiary syllogisms). Next we show that God does have right moments for action (and here another string of subsidiary syllogisms). We conclude that right moments for action etc. etc.

But the leading syllogism is just one syllogism, like each of the subsidiary syllogisms. Local formalising in this case tells us that the choices of domains and terms for formalising the subsidiary syllogisms don't have to agree with the domain and terms chosen for formalising the leading syllogism. (The previous sentence is my point, not Aristotle's.)

Other texts confirm that local formalising is typical of the aristotelian tradition. Here is Proclus in the 5th century, describing the procedures of the commentator Iamblichus in the early 4 th century:

That method of dividing the dialogue seems to me to be the most perfect of all, which the philosopher Iamblichus also fixed on. This bases itself on the actual subject-matter and gathers into three sections the whole substance of the work, and relates to this the division according to syllogisms and that which takes (14) account of the forms of discourse. ... How then do we say that the dialogue is divided into its immediate and most basic parts? ... [T] here comes first therefore one section which removes ignorance from the Reason and does away by means of a copious variety of syllogisms with all those obstacles to knowledge which exist as the result of generation.

(Proclus In Alcibiadem Fr. 2, in [8] p. 73.) The syllogisms correspond to the 'immediate and most basic parts' of the argument being studied.

Leibniz saw formalising as a kind of paraphrase. (For example, raw natural language arguments are not 'transmutatae in aliam formam, scholarum more', [22] p. 36.) The paraphrases that particularly interested him were those where the salient parts of an inference are brought into the nominative case. We will see where this viewpoint comes from in $\S 6$ below. The effect is that in general an analysed piece of reasoning consists of interleaved steps: 'grammatical' steps of paraphrasing, and 'syllogistic' steps of 
logical reasoning. Thus:

It should also be realized that there are valid non-syllogistic inferences which cannot be rigorously demonstrated in any syllogism unless the terms are changed a little, and this altering of the terms is the non-syllogistic inference. There are several of these, including arguments from the direct to the oblique - e.g. 'If Jesus Christ is God, then the mother of Jesus Christ is the mother of God'. And again, the argument-form which some good logicians have called relation-conversion, as illustrated by the inference: 'If David is the father of Solomon, then certainly Solomon is the son of David'. ... ([23] 479f.; his italics.)

And in the context of his plan for a universal language:

So we can do without adverbs, most conjunctions and all interjections; and even cases and times and persons. This is grammatical analysis ... After this purely grammatical analysis comes Logical analysis. ([22] p. 353.)

The paraphrases that Leibniz describes are all at the level of single sentences. They bring the premises of an inference to a form where the traditional rules of logic apply. So again we have local formalising.

Now if syllogisms are patterns for the 'immediate and most basic parts' of an argument, do they correspond to modern valid sequents, or to modern inference rules?

The distinction between valid sequents and inference rules is twentieth century; we can reasonably project it back to Frege, but hardly further. So there is some anachronism in thinking of syllogisms as corresponding to either of the two. But once the question is raised, it must surely be clear that they correspond more closely to inference rules than to valid sequents. They are more complex than we like our rules of inference to be; but this is precisely Hilbert's observation that traditional logic failed to analyse down to simple logical principles.

In fact it could be argued that the profusion of more complicated inference patterns in the later centuries of the aristotelian tradition is less a sign of logical progress, and more a testimony to the failure to reach primitive rules that would have allowed these patterns to be generated. But I come back to this question at the end of the paper.

Inference rules normally contain just one active variable. First-order translations of categorical syllogisms normally have a single active variable 
too, which is why Hilbert uses monadic logic to express them. But modern inference rules usually carry along a set of individual parameters, either universally quantified or as formal parameters. For example Shoenfield [34] p. 21 has an inference rule

If $x$ is not free in $\mathrm{B}$, infer $\exists x \mathrm{~A} \rightarrow \mathrm{B}$ from $\mathrm{A} \rightarrow \mathrm{B}$.

where A and B are formulas with any number of free variables. In exactly the same way, the terms in a natural language syllogistic inference can have any number of formal parameters in them.

In practice the best aristotelian logicians could handle parameters inside terms, even if they had no good theoretical account of them. A note recently published by Mugnai [28] p. 153 shows Leibniz confidently using a formal parameter 'Titius' that is clearly part of the interpretation of a syllogistic term. (Who on earth is Titius? Exactly so-formal parameters don't name individuals.) Ibn Sīnā constantly refers to implicit parameters in terms, and he has a modality d $\bar{a}^{\prime} i m a n$ which is adequate for universally quantifying them.

In short, the contrast 'traditional logic monadic, modern logic polyadic' is an illusion. If Kant wasn't able to put relational arguments into syllogistic form, this is only one of many pieces of evidence of the sad decline of traditional logic in its later centuries.

\section{Comparison of local and global formalising}

A few things are harder for the local formaliser than they are for modern logicians. The local formaliser has to break each complex argument down to simple self-contained pieces. This prevents her from making an assumption and then discharging it seventeen steps later-a device that Euclid certainly uses in the Elements, for example when he argues by reductio ad absurdum. This is why traditional logicians sometimes explained reductio ad absurdum by taking the false assumption not as a premise but as the antecedent of a conditional. (One of the clearest accounts along these lines, before Frege, is by Ibn Sīnā in his Qiyās viii.3, cf. [19].)

On the other hand the ability to shift to a new formalisation at each step of an argument certainly makes possible some things that we wouldn't dream of doing in a standard first-order formalisation. The clearest cases are where the reformalisation actually changes the universe of discourse. Let me give three examples. 


\subsection{Changing the domain to pairs of elements}

This change was used to handle binary relations. Alexander of Aphrodisias has a clutch of examples in his commentary on Prior Analytics i in the 2nd century AD. For example:

"This individual (for example, A) has the same parents as that one (for example, B); but also B has the same parents as $C$; therefore $A$ has the same parents as C."

(18) What is left out for there to be a syllogism is the universal premiss which says 'All things which have the same parents as someone are siblings', to which one adds the divided premiss made one and saying that $\mathrm{A}$ and $\mathrm{C}$ have the same parents as B. In this way it follows that $\mathrm{A}$ and $\mathrm{C}$ are siblings. ([26] p. 28f.)

Thus Alexander moves to a universe of pairs, so that he can formulate the syllogistic sentence 'Every pair $(x, y)$ of people such that both $x$ and $y$ are siblings of the same person, is a pair such that they are siblings of each other'.

A more clear-headed example is in Ibn Sīnā:

When you say 'If a line falls on two lines in such a way that the two angles which are on one side etc., then the two lines are par-

(19) allel', this can be paraphrased as a predicative proposition thus: 'Every pair of lines, on which a line falls in such-and-such a way, is a parallel pair'. (Ibn Sīnā Qiyās [21] 256.12-15.)

Probably Proclus has a similar device in mind in his syllogistically-arranged commentary on Aristotle's Physics, [32] I.1:

Any pair $\mathrm{AB}$ of things that touch each other have a common boundary.

So this device seems to have been standard equipment before the Scholastic period. Perhaps it's only my ignorance that prevents me giving Scholastic examples too.

Ian Mueller [27] p. 42 has described arguments along the lines of (18) as 'wrong'. The reason is that in order to bring the premise 'Every pair ...' 
into play, one needs a further inference of the form

$x$ and $y$ are both siblings of $z$; therefore both $x$ and $y$ are siblings

of the same person.

But this inference 'depends on the relations among the three' people $x, y, z$ 'and not on properties of them taken as pairs'. (He takes a slightly different example but his point is the same.) Of course Mueller is right that Alexander's inference needs to be combined with (21). But under local formalising there is no problem about doing this. The inference (21) is a special case of ' $z$ is a B; therefore something is a $\mathrm{B}$ ', with the single active variable $z$; the variables $x$ and $y$ are formal parameters. Challenged to justify this inference by syllogisms, a traditional logician can answer at once with a syllogism in mood Darapti:

(22) $z$ is a B. $z$ is a thing. Therefore some thing is a B.

This syllogistic argument is embarrassing for modern logicans because it throws a harsh light on the traditional failure to analyse down to simple principles; but its validity is impeccable. I take Mueller's discussion not as a demonstration that Alexander's argument is wrong, but as further evidence for the use of local formalising.

Later in the same article Mueller [27] p. 62f criticises similar arguments in Alexander and Galen as 'ridiculous'. I think this is unfair. Formal devices often do seem silly when they are detached from the formal machinery where they belong.

Note once again that the dichotomy 'traditional monadic, modern relational' is an illusion.

\subsection{Changing the universe to situations}

This device often appears under the name of 'reduction of hypotheticals to categoricals'. Briefly, we translate $p \rightarrow q$ into the form 'Every situation in which $p$ is true is a situation in which $q$ is true'. The reduction was taken for granted by Ibn Sīnā (at least as a heuristic, for example Qiyās [21] 415.10f) and Wallis ([37] Thesis Secunda), and advertised by Boole [5] p. 49 (where he switches his Universe to 'all possible cases and conjunctures of circumstances'). Particularly interesting is Boole's comment

it is necessary that each sign should possess, within the limits of

the same discourse or process of reasoning, a fixed interpretation ([5] p. 26). 
taken with the fact that Boole never mixes syllogistic reasoning with propositional reasoning. Apparently he regarded a switch from a quantifier rule to a propositional rule as a change of 'discourse or process of reasoning'.

\subsection{Incorporating a metadomain}

For example Buridan's version of reductio ad absurdum ([6] 5.10.6) avoids actually making the false assumption. Instead it deduces the conclusion $C$ from the metalevel fact that 'we can prove that the contradictory [of $C$ ] is impossible'.

Global formalising appeared quite suddenly, towards the end of the 19th century, in the work of Frege and Peano. Its success was so great that most modern logicians assume it was always the aim of logic. I leave aside Peano for reasons of space, and concentrate on Frege.

Frege's early work in logic was in aid of showing that the truths of arithmetic are analytic, i.e. definable and provable in general logic. He found traditional logic seriously inadequate for showing this. He complained about the ambiguities of natural language. But he reserved his chief ire for local formalising. Sometimes he attacked the syllogistic/non-syllogistic alternation that Leibniz had described:

[Our doubt about the analytic character of arithmetic] can only be canceled by means of a gapless chain of deductions, so that no step could appear in it that is not in accordance with one of a few inference principles that are recognized as purely logical. ([10] $\S 90)$.

Sometimes he condemned the changes of 'viewpoint', in words that seem to be aimed at shifts like those discussed earlier in this section:

We cannot give too many warnings against the danger of confusing points of view and switching from one question to another, a danger to which we are particularly exposed because we are accustomed to thinking in some language or other and because grammar ... is a mixture of the logical and the psychological. ('Logic', [11] p. 6.)

One should add that global formalising, which Frege embraced from his earliest published work in logic, doesn't remove all appeals to linguistic intuition. Instead it concentrates these appeals at the places where axioms are chosen or definitions are introduced-one has to use intuition to check 
that the formal definition matches the informal notion that it was intended to formalise. I believe Frege himself took this fact on board only in late work, unpublished in his lifetime ('Logic in mathematics', [11] p. 208ff).

In the light of all this, does it seem likely that Ibn Sīnā really had the logical resources to validate the arguments used by Euclid? I think there are too many rough edges in Ibn Sīnā's procedures to make this a sensible question. A more profitable approach would be to take a logical calculus that certainly is sufficient for Euclid's arguments, say a suitable Hilbertstyle calculus with axioms for real-closed fields, and prove a theorem to the effect that any sequent provable in this calculus is also provable using such-and-such kinds of syllogism and such-and-such kinds of reformalising between steps. After the theorem is proved, one can compare the devices that it invokes with the ones that Ibn Sīnā actually had. At least until this has been done, I wouldn't criticise Ibn Sīnā for supposing that he had in principle all the logical tools needed for the job.

It may be relevant that on Reviel Netz's analysis ([29] p. 197) the majority of assertions in two sample sections of Euclid's Elements are about equivalences. It was precisely to handle equivalences that Alexander of Aphrodisias and Ibn Sīnā passed to a domain of pairs, as we saw earlier in this section.

\section{Top-level processing}

Setting out of terms (section $\S 2$ above) rapidly disappeared from the scene. After Aristotle, we have little evidence of its use until Boole reintroduced it in 1854 ([4] pp. 33, 57, 59 for example).

In passing I note that there may be a historically interesting difference between Aristotle's version of setting out and Boole's. Netz ([29] 2.3.1 'The semiotics of letters') argues, on the basis of the phrases that they use, that for early Greek geometers a letter didn't stand for an item in a diagram, it stood next to the item and thereby served as a reference point for the item. Then Netz notes that Aristotle uses exactly those same phrases in his setting out. This seems to me evidence that Aristotle did actually draw diagrams like (8), writing the letters next to phrases in order to link them with the phrases. So the diagrams were essentially macros for constructing the formal paraphrases, and this might help to explain why they disappeared so soon.

Boole's notion was different. In the opening paragraph of his [5] (p. 3) 
he had announced his allegiance to George Peacock's theory of interpretations of the symbols of Symbolical Algebra. In that context, setting out of terms is not just a matter of using letters as labels; it involves interpreting the letters as meaning what the associated phrases mean. Boole's version of setting out is much closer to model theory than Aristotle's was.

But to return to our main theme: instead of setting out terms, traditional logicians after Aristotle normally went straight to the formal paraphrase. This works, provided that the formal paraphrase is in a form where one can read off the terms. Logicians writing in Greek, Latin or German normally ensured this by using paraphrases of the form

$$
\text { Some/every } A \text { is/isn't a } B \text {. }
$$

where the subject term $A$ and the predicate term $B$ are picked out by being in the nominative case. Arabic doesn't allow this strategy: Arabic translations of (26) are liable to throw either of $A$ and $B$ into the accusative or the genitive. So Ibn Sinna adopts the alternative convention that the formal paraphrase is a topic-comment sentence (mubtada'-kabar, a kind that occurs frequently in Arabic), and he reads off the topic as subject and the comment as predicate (e.g. [20] 31.17-32.2). The implications of this choice for logic are curious, but not our concern here. The important point for us is that in both East and West one formalised by adopting a paraphrase that brought the sentences to a certain grammatical form where both subject and predicate were at the top level of the syntactic analysis.

In both East and West one meets a tendency to think that somehow the formal paraphrase is the 'real' form in which the syllogistic inference takes place, or that the mind operates directly with the formal paraphrase. I use the name top-level processing for this tendency. In Ibn Sinna it becomes part of a full-blown theory about how the mind processes the raw data of inference; Ibn Sinnā believes that the internal parts of the subject and predicate are in some sense unavailable to the mind while it syllogises. In Leibniz it appears as a conviction that the way to handle intractable inferences is to get the relevant parts into the nominative case.

We are dealing here with something not quite fully articulated. It's not just that, as Van Benthem rightly says, syllogisms were

a method for one-step analysis of statements of any kind into one layer of quantification ([36] p. 23).

The damaging extra ingredient in top-level processing was the conviction that for some deeper reason, inferences had to be at the top syntactic level. 
The problem this created for logic was that some inferences do require dipping down below the top syntactic level. For example if we say ' $a$ is greater than $b^{\prime}$, the term ' $b$ ' will not be in the nominative and it will be an internal part of the kabar. So it will supposedly be invisible to logical processing unless we paraphrase, either bringing ' $b$ ' itself to top level, or switching to pairs and taking 'the pair $(a, b)^{\prime}$ ' as subject. Both these fixes are possible and were used. But they are a strong hindrance to free-wheeling arguments with relations, and they interrupt the logical process with an appeal to linguistic intuition.

Frege was the first to see this clearly. In Begriffsschrift [9] $§ \S 3,9$ in 1879, he discarded the notion of subject and took all arguments of a relation to be at the same level. He also introduced rules like that for equality ([9] $\S 20)$. He wrote it as an axiom, but for ease of comparison I rephrase it as an inference rule:

$$
(c=d), f(c) \vdash f(d) .
$$

where $c$ can be arbitrarily deep down in the syntax of $f(c)$. (Or rather, he claimed that in 'the content of a possible judgement' we can choose where we want to split off the replaceable argument; see for example [11] p. 16ff, and Danielle Macbeth [25] p. 39ff for a discussion. It's as if he wanted to say that we can only reason at the top level, but the top level is wherever we want to put it. The psychological pull of top-level processing is so strong that Frege has to re-introduce it in metaphor at the same time as he is dismantling its literal application.)

In his chapter 'Properties of elective functions' ([4] p. 60ff) Boole made substitutions at arbitrary depth in terms. But he was just copying the standard practice of mathematical analysts, apparently without any realisation of what this move implies for logic.

\section{Monotonicity and natural logic}

There were some attempts to break away from top-level processing already in the early fourteenth century. The ineptitude of these attempts is a neat illustration of the weaknesses of traditional logic in its later centuries.

The Scholastics had noticed that all categorical syllogisms are instances of a common pattern. Most of these syllogisms contain a premise of the form 'Every $A$ is a $B^{\prime}$. Then the passage from the other premise $\phi$ to the conclusion is got by replacing $A$ by $B$ in $\phi$, or vice versa. If $A$ is replaced 
by $B$ we say we are using upward monotonicity at $A$; in the other direction we are using downward monotonicity at $B$. Downward monotonicity applies when $B$ is 'distributed' in $\phi$; upward monotonicity applies when $A$ is 'undistributed' in $\phi$. For each syllogistic sentence it was specified which terms are distributed; a subject term is distributed if it is universally quantified and undistributed if it is existentially quantified, while a predicate term is distributed if the sentence is negative and undistributed otherwise. Variants of this procedure work for the remaining categorical syllogisms. The general procedure was sometimes described as dici de omni et nullo.

In the early 14th century some logicians tried to apply monotonicity to terms that were buried deeper in the syntactic structure of a sentence, and couldn't be brought to top level by paraphrasing. These attempts continued till the mid 19th century; for example De Morgan tried to justify (2) by a monotonicity argument. But they were largely failures, though at least three approaches were tried.

First, Walter Burley ([18] p. 95f) broke down the sentence involved until he reached a piece where the term in question was at top level, so that he could apply monotonicity straightforwardly. Then he reassembled the sentence step by step. This is sound procedure, but it involves handling formal parameters when one removes a quantifier to reach the required piece of the sentence. Burley was easily confused by formal parameters ([18] p. 92f).

Unlike Burley, some authors really did want a monotonicity rule that applied directly to terms below the top level. So they had to decide what was the appropriate generalised definition of 'distributed'. As we saw, 'distributed' is defined one way for the subject term and another way for the predicate term. (In fact a correct statement of the definition for the predicate works also for the subject; but this wasn't realised until the 20th century. Briefly, a term in a sentence is distributed if it occurs only negatively, and undistributed if it occurs only positively. ...) Some logicians tried to generalise the definition given for subject terms, while others tried to generalise that given for predicate terms.

Thus De Morgan in 1847 ([7] p. 114f) explained that a term allows downward monotonicity if it is 'used universally' and upwards if it is 'used particularly' (i.e. existentially). Similar ideas can be found earlier in Buridan. To make this seem to work in the cases where he wanted to apply it, he had to invent quantifiers where there clearly weren't any. He was trapped by his persistent habit of preferring metaphors and analogies to precise statements.

In the mid 14th century Richard Billingham ([33] p. 51) declared that we 
can use upward monotonicity at positively occurring terms. This is correct, and it used to impress me greatly before I realised that he was putting into a neat form observations about syllogisms that were made already in the Abbreviatio Montana from the late 12th century. We don't know that he had any intention of applying the rule to anything except predicates in syllogisms. (See the reference and discussion at [18] p. 87.)

Leibniz did better: he allowed upward monotonicity at a term 'in every ... affirmative proposition where the term occurs as a predicate' ([24] p. 38). His examples suggest that he meant a term which occurs as predicatepossibly of a subclause-in a sentence with no negations. The subclause could be inside the scope of several quantifiers, universal or existential. This definitely breaks the top-level restriction, but it is still very limited. Also Leibniz gave no hint of how to prove its correctness; with complicated patterns of quantifiers one can hardly rely on intuition to confirm it.

The natural 20th century response to all this is to combine the approaches of Burley, Billingham and Leibniz. In a suitably regimented form of natural language, one defines which occurrences of terms are positive in a sentence and which are negative, by induction on the syntax. Then one introduces a monotonicity rule along the lines:

Suppose $A$ has only positive occurrences in $\phi(A)$ and $B$ has only negative occurrences in $\psi(B)$. Then:

1. From 'Every $A$ is a $B^{\prime}$ and $\phi(A)$ we can infer $\phi(B)$;

2. From 'Every $A$ is a $B^{\prime}$ and $\psi(B)$ we can infer $\psi(A)$.

This works, and it wraps up the logic beautifully. Van Benthem [36] gives some references and some examples.

\section{$8 \quad$ Natural?}

But now I want to raise a final question which is only incidentally about traditional logic.

It's true that the monotonicity rules of 'natural logic' are based on ideas from traditional logic, and that traditional logic was done in natural language. But aside from this link via traditional logic, I'm not convinced that there is any direct connection between natural language and these rules. Why should we think that this 20th century updating of monotonicity is 'natural' in any sense in which natural languages are 'natural'? ... It seems to me that identifying occurrences at any significant depth in a sentence as positive or negative just isn't one of our inbuilt skills. I can quote at least 
one traditional logician in my support: already in the 12th century John of Salisbury suggested that if you want to use multiple nesting of negations, you may need to carry around a calculating device to keep track of the nesting ([18] p. 86).

It's an empirical question what kinds of reasoning people perform smoothly and reliably, and what kinds they find 'natural'. There already is some empirical evidence out there. For example Oakhill et al. [30] p. 126f gave their subjects the premises of some syllogisms and asked them to say what conclusions follow, and found after the experiment that there were too few cases in which the correct conclusion was produced to warrant an analysis'; how does this square with a blanket claim that syllogistic reasoning is 'natural'? (I thank Jane Oakhill for calling this result to my attention.) How does this square with a blanket claim that monotonicity reasoning is 'natural'? In Oakhill's case the substitutions are not even deep in the sentences.

There is experimental work to be done here. Let me make two observations about possible experiments.

The first is that it might clear the air to compare the monotonicity rule (29) with Frege's rule (28). They are both rules that apply to occurrences arbitrarily deep in a sentence. My prediction is that in terms of any reasonable notion of naturalness (reliability, speed, confidence ...) Frege's rule will come out more natural than the monotonicity rule. I did make some preliminary soundings among some experts in psycholinguistics and the psychology of reasoning, to see whether any relevant work has been done yet. Nobody could point me to any.

The second is that it really doesn't make too much sense to ask what kinds of reasoning are natural without discussing the context where the reasoning is called for, and the intentions and expectations of the reasoner. (See Stenning and Van Lambalgen [35] passim.) Our reasoning powers are highly adaptable. I wouldn't expect that nature follows Hilbert's ideal, giving us a small number of simple reasoning principles that allow us to generate all the inferences that we need to make. Much more likely is that nature equips us with a large number of relatively complex reasoning patterns, corresponding to the lavishness of natural language and the variety of situations in which we use it. I would expect that if we really do succeed in identifying those reasoning patterns that are 'natural', we will find that they form a hugely richer collection than the rather stunted list that came down to us from Aristotle. ... 


\section{References}

[1] Alexander of Aphrodisias, Alexandri in Aristotelis Analyticorum Priorum Librum I Commentarium, ed. Maximilian Wallies, Commentaria in Aristotelem Graeca 2.1, Reimer, Berlin 1883.

[2] Aristotle, The Complete Works of Aristotle, Vol. 1, ed. Jonathan Barnes, Princeton University Press, Princeton NJ 1984.

[3] Anicius Manlius Severinus Boethius, De Topicis Differentiis, translated and edited by Eleonore Stump, Cornell University Press, Ithaca 1978.

[4] George Boole, An Investigation of the Laws of Thought on Which are Founded the Mathematical Theories of Logic and Probabilities, Dover, New York 1958 (original 1854).

[5] George Boole, The Mathematical Analysis of Logic: Being an Essay towards a Calculus of Deductive Reasoning, Macmillan, Barclay and Macmillan, Cambridge 1947.

[6] John Buridan, Summulae de Dialectica, trans. Gyula Klima, Yale University Press, New Haven 2001.

[7] Augustus De Morgan, Formal Logic: The Calculus of Inference, Necessary and Probable, Taylor and Walton, London 1847.

[8] John M. Dillon, Iamblichi Chalcidensis in Platonis Dialogos Commentariorum Fragmenta, Brill, Leiden 1973.

[9] Gottlob Frege, Begriffsschrift, Olms, Hildesheim 1998 (original 1879).

[10] Gottlob Frege, The Foundations of Arithmetic, trans. Dale Jacquette, Pearson, New York 2007 (original 1884).

[11] Gottlob Frege, Posthumous Writings, ed. Hans Hermes et al., trans. Peter Long and Roger White, Blackwell, Oxford 1979.

[12] Michael Friedman, 'Kant's theory of geometry', The Philosophical Review 94 (1985) 455-506.

[13] L. T. F. Gamut, Logic, Language, and Meaning, Vol. 1: Introduction to Logic, University of Chicago Press, Chicago 1991.

[14] Niels Jørgen Green-Pedersen, The Tradition of the Topics in the Middle Ages, Philosophia Verlag, Munich 1984. 
[15] Dimitri Gutas, Avicenna and the Aristotelian Tradition: Introduction to Reading Avicenna's Philosophical Works, Brill, Leiden 1988.

[16] Thomas Heath, Mathematics in Aristotle, Thoemmes, Bristol 1998.

[17] D. Hilbert and W. Ackermann, Grundzüge der Theoretischen Logik, Springer, Berlin 1928.

[18] Wilfrid Hodges, 'Detecting the logical content: Burley's 'Purity of Logic' ', in We Will Show Them! Essays in Honour of Dov Gabbay on his 60th Birthday, Vol. 2, ed. Sergei Artemov et al., College Publications, London 2005, pp. 69-115.

[19] Wilfrid Hodges, 'Ibn Sīnā on reductio ad absurdum' (preprint).

[20] Ibn Sīnā, $A l^{c}{ }^{c} I b \bar{a} r a$, ed. Ibrahim Madkour et al., Dār al-Kātib al-c Arabī lil-Tabā $\bar{a}^{c}$ wal-Našr, Cairo 1970.

[21] Ibn Sīnā, Al-Qiyās, ed. Ibrahim Madkour et al., Našr Wizāra al-Ṭaqāfa wal-'Iršād al-Qūmī 1964.

[22] G. W. Leibniz, Opuscules et Fragments Inédits, ed. Louis Couturat, Alcan, Paris 1903.

[23] G. W. Leibniz, New Essays on Human Understanding, translated and edited by Peter Remnant and Jonathan Bennett, Cambridge University Press, Cambridge 1996.

[24] G. W. Leibniz, G. G. Leibnitii Opera Omnia vol. 6, ed. L. Dutens, Fratres de Tournes, Geneva 1768.

[25] Danielle Macbeth, Frege's Logic, Harvard University Press, Cambridge Mass. 2005.

[26] Ian Mueller, Alexander of Aphrodisias, On Aristotle Prior Analytics 1.3246, Duckworth, London 2006.

[27] Ian Mueller, 'Greek mathematics and Greek logic', in J. Corcoran ed., Ancient Logic and its Modern Interpretations, Reidel, Dordrecht 1974, pp. 35-70.

[28] Massimo Mugnai, Leibniz' Theory of Relations, Steiner, Stuttgart 1992.

[29] Reviel Netz, The Shaping of Deduction in Greek Mathematics: A Study in Cognitive History, Cambridge University Press, Cambridge 1999. 
[30] J. V. Oakhill, P. N. Johnson-Laird and Alan Garnham, 'Believability and syllogistic reasoning', Cognition 31 (1989) 117-140.

[31] Peter of Spain, Tractatus, ed. L. M. de Rijk, Van Gorcum, Assen 1972.

[32] Proclus Diadochus Lycius, Elementatio Physica, ed. Helmut Boese, Akademie-Verlag, Berlin 1958.

[33] L. M. de Rijk, Some 14th Century Tracts on the Probationes Terminorum, Ingenium, Nijmegen 1982.

[34] Joseph R. Shoenfield, Mathematical Logic, Addison-Wesley, Reading Mass. 1967.

[35] Keith Stenning and Michiel van Lambalgen, Human Reasoning and Cognitive Science, MIT Press, Cambridge Mass. 2008.

[36] Johan van Benthem, 'Natural logic: A view from the 1980s', in Logic, Navya-Nyāya and Applications: Homage to Bimal Krishna Matilal, ed. Mihir K. Chakraborty et al., College Publications, London 2008, pp. 2142.

[37] John Wallis, Institutio Logicae, Lichfield, Oxford 1702.

[38] Wikipedia, http://en.wikipedia.org/wiki/Term_logic, 15 June 2009. 